\title{
Production of Didymella rabiei Pseudothecia and Dispersal of Ascospores in a Mediterranean Climate
}

\author{
E. Gamliel-Atinsky, D. Shtienberg, H. Vintal, Y. Nitzni, and A. Dinoor
}

\begin{abstract}
First, second, third, and fourth authors: Department of Plant Pathology, ARO, the Volcani Center, P.O. Box 6, Bet Dagan 50250; and fifth author: Department of Plant Pathology and Microbiology, Faculty of Agricultural, Food and Environmental Quality Sciences, the Hebrew University of Jerusalem, P.O. Box 12, Rehovot 76100, Israel.
\end{abstract}

Accepted for publication 9 July 2005.

\begin{abstract}
Gamliel-Atinsky, E., Shtienberg, D., Vintal, H., Nitzni, Y., and Dinoor, A. 2005. Production of Didymella rabiei pseudothecia and dispersal of ascospores in a Mediterranean climate. Phytopathology 95:1279-1286.

Temperature and wetness conditions required for development and maturation of Didymella rabiei pseudothecia were determined in a series of experiments conducted in controlled-environmental conditions. Initial stages of pseudothecium formation occurred at temperatures ranging from 5 to $15^{\circ} \mathrm{C}$. Incubation at low temperatures was essential for subsequent pseudothecium maturation. This requirement was satisfied for chickpea stem segments incubated at 5 or $10^{\circ} \mathrm{C}$ for three consecutive weeks or during periods of 3 or 5 days, separated by periods at higher temperatures. Following the low-temperature requirement, subsequent
\end{abstract}

ABSTRACT pseudothecium development was independent of temperature in the range tested $\left(5\right.$ to $\left.20^{\circ} \mathrm{C}\right)$. Wetness was essential for pseudothecium production: pseudothecia formed and matured on stem segments maintained continuously wet but also on those exposed to periods of three or five wet days, separated by dry periods. The dispersal of D. rabiei ascospores was studied using chickpea plants as living traps in the field. Trap plants were infected mainly when exposed during rain but also in rainless periods. Results of this study enabled us to describe the developmental events leading to the production of the teleomorph stage and the dispersal of ascospores by $D$. rabiei in the Mediterranean climate of Israel.

Additional keywords: Ascochyta blight, Cicer arietinum, forecasting model, management.
Didymella rabiei (Kovachevski) v. Arx. (synonym Mycosphaerella rabiei Kovachevski [anamorph Ascochyta rabiei]), the causal agent of Ascochyta blight is the most destructive foliar disease of chickpea (Cicer arietinum L.) worldwide. The pathogen is heterothallic with a unifactorial (bipolar) homogenic mating-incompatibility system; the two mating types have been referred to as MAT1-1 and MAT1-2 (2,32). The teleomorph was first recorded by Kovachevski (14) on overwintering chickpea debris in Bulgaria. It was subsequently reported on chickpea debris in Russia (7), Greece (33), Hungary (15), Spain (20,21), Syria (8), Iran, (13), Turkey (12), the United States (11), Canada (1), and recently in Western Australia (4). Pseudothecial formation begins in autumn, and ascospores are discharged from the end of winter through spring. Pseudothecial maturation typically peaks at the beginning of spring, and ascospore release decreases drastically or stops altogether by the beginning of summer (10,31). After exhaustion of the pseudothecia, no more ascospores are produced and the pseudothecial walls degenerate $(10,21,22,30,31)$. The ascospores are dispersed by wind and are a major source of initial inoculum in chickpea fields in the Pacific Northwest United States (10) and Spain (31).

Some controlled-environment studies have been carried out in the United States (30) and Spain (21) to determine the environmental factors that promote the production of the teleomorphic stage of $D$. rabiei on chickpea debris. Temperature and moisture (wetness) were found to be key factors controlling pseudothecium formation and maturation. If moisture requirements are satisfied, pseudothecium development may be initiated at temperatures between 5 and $25^{\circ} \mathrm{C}$, but further development is regulated by low

Corresponding author: D. Shtienberg; E-mail address: danish@volcani.agri.gov.il

DOI: 10.1094/PHYTO-95-1279

(C) 2005 The American Phytopathological Society temperatures. Optimal temperatures for pseudothecium maturation are between 5 and $10^{\circ} \mathrm{C}(21,30)$. Temperatures above $15^{\circ} \mathrm{C}$ are detrimental for maturation: in $34 \%$ relative humidity $(\mathrm{RH})$, the pseudothecia remain at the initial stages of development and in $100 \% \mathrm{RH}$, their contents degenerated and no ascospores were produced (21). Once development of the ascus and ascospores are initiated, further pseudothecium development appears to be less dependent on temperature. At 5 to $10^{\circ} \mathrm{C}$, pseudothecia develop and mature in approximately 7 to 8 weeks $(21,30)$.

If temperature requirements are satisfied, moisture, either continuous or alternated (wet/dry cycles), is a fundamental requirement for formation of pseudothecia. No pseudothecia develop in air-dried chickpea stems, and pseudothecial development ceases when infested debris containing pseudothecia at various developmental stages is air dried $(21,30)$. Continuous wetness or wet/dry cycles are a prerequisite for pseudothecium formation and maturation in Venturia inaequalis $(9,23)$, Pleospora allii (25), and M. citri (19).

Production of D. rabiei pseudothecia was also studied in field conditions $(10,22)$, and in general, the results corroborated those obtained in controlled conditions. Pseudothecial maturation and ascospore liberation were more uniform and more asci developed per pseudothecium in the cooler study sites. The importance of moisture for pseudothecium development was noted as well: no further pseudothecium development was observed during dry periods, and the latest pseudothecium development occurred during years with lower than average spring rainfall (22).

In mature pseudothecia, discharge of ascospores is affected by numerous factors among which are temperature, light, vibration, and electrostatic charge (24); however, the main factor is moisture that is usually provided by rain. The sequence of events leading to discharge of ascospores from moistened pseudothecia was described in detail by Gadoury et al. (3) for V. inaequalis. The role of rain in ascospore discharge has been demonstrated for $D$. ra- 
biei $(10,31)$ and also for other pseudothecium-producing fungi such as M. citri (18), M. populorum (16), Anisogramma anomala (24), Physalospora obtusa (29), Botryosphaeria dothidea (29), and $P$. allii (25).

Chickpea is one of the main legume crops in Israel where winter sowing has been practiced for approximately 35 years. The seeds are sown in mid-winter (December-January) and the crop matures and is harvested in early summer (June-July). Ascochyta blight is the most important foliar disease and yields may be reduced substantially if the disease is not properly managed (27). The teleomorph stage of the pathogen was first identified in Israel in 1995 (28) and continued to be observed thereafter on Ascochyta blight-infested debris collected from all chickpea production areas of the country (D. Shtienberg, unpublished data). Several lines of evidence suggest that the teleomorph stage of $D$. rabiei plays a significant role in Ascochyta blight epidemiology in Israel. Since only certified seed produced from noninfested fields are used and chickpea is grown in (at least) a 4-year rotation, the likelihood of the anamorph stage being an important source of initial inoculum is small. However, severe Ascochyta blight epidemics occur regularly in all chickpea-production areas of the country (even in fields where chickpea is grown for the first time). Moreover, the pattern of infection in diseased fields suggests that the teleomorph rather than the anamorph usually serves as the source of initial inoculum. When infected seedlings (germinated from Ascochyta blight-infested seeds) are the initial source of inoculum, distinct disease foci are observed in the field, and plants located in the center of each focus are infected on their lower parts (17). In chickpea fields infected by ascospores, infections are often observed on the upper parts of the plant canopy, and diseased plants are randomly distributed over the field. In addition, in ascospore-infected fields, the disease may be initiated at any stage of crop development, whereas in seed-infected fields, diseased plants are observed soon after emergence.

The observation that the teleomorph stage of $D$. rabiei plays an important role in Ascochyta blight epidemiology in Israel raises question because the environmental conditions in the main chickpea-production areas of the country are presumably unsuitable for pseudothecium formation and maturation. The climate in Israel is Mediterranean: winter temperatures are mild and there are long rainless periods between the infrequent rain events. The long-term average temperatures in the winter months (November to March) in Bet Dagan (located in the coastal plain, an important chickpea production area) are $17.9,14.1,12.5,12.6$, and $14.4^{\circ} \mathrm{C}$, respectively. Prolonged periods with temperatures of $\leq 10^{\circ} \mathrm{C}$, which are essential for pseudothecium maturation $(21,30)$, are uncommon and, if they occur, prevail for only a few days in each season. For example, in the winter of 2002-2003 there were 4 days and in the winter of 2003-2004 there were 5 days with an average daily temperature of $\leq 10^{\circ} \mathrm{C}$. The other essential requirement for pseudothecium formation and maturation is moisture: infested chickpea debris must be wet for the duration of pseudothecium development (6 to 8 weeks) or at least must be exposed to alternating weekly cycles of wetting and drying $(21,30)$. It is apparent that the frequency of rain events in the main production areas in Israel does not satisfy this requirement: for example, on average there are 38.9 days with $\geq 0.5 \mathrm{~mm}, 23.4$ days with $\geq 5 \mathrm{~mm}$, and 15.6 days with $\geq 10 \mathrm{~mm}$ of rain in the five winter months in Bet Dagan.

There are two possible explanations for this. The first relates to possible variability among pathogen populations; it is possible that $D$. rabiei populations in different regions have adapted to the local environmental conditions. Thus, the ecological requirements for pseudothecium production of isolates from Israel would differ from those of isolates from other climates. The second possibility is that the ecological requirements of isolates from differing climates are similar, but that pseudothecia may form and mature under marginal environmental conditions that were not included in the studies conducted previously $(21,30)$. For example, the low-temperature and wetness requirements for pseudothecium formation and maturation could be satisfied if the infested debris were exposed to wetness and low temperatures for short, interrupted periods. Such information is crucial for the development of strategies for Ascochyta blight management, such as forecasting systems for initiating fungicide sprays. Likewise, understanding the factors governing ascospore discharge and dispersal in time and space is required for determining the need for subsequent fungicide sprays. Thus, the objectives of the current study were to: (i) quantify the effects of temperature and interrupted wetness periods on the formation and maturation of D. rabiei pseudothecia in Israel; and (ii) determine the temporal and spatial pattern of dispersal of D. rabiei ascospores. Preliminary results have been published (6).

\section{MATERIALS AND METHODS}

Fungal isolates. The mating type of Israeli $D$. rabiei isolates was determined as follows. Chickpea stems bearing lesions with pycnidia of D. rabiei were sampled from 1997 to 1999 in commercial fields naturally infected with Ascochyta blight. Two- to four-cm-long stem segments were air dried and surface disinfected with a domestic bleach solution (1\% sodium hypochlorite), washed with sterile distilled water, and plated on potato dextrose agar (PDA; Difco Laboratories, Detroit, MI). Conidia were harvested from the cultures by agitating small pieces of mycelium and pycnidia-bearing agar in a glass tube containing $2 \mathrm{ml}$ of sterile water. The resulting conidial suspension was then evenly dispersed on PDA and single colonies were transferred and incubated at 21 to $23^{\circ} \mathrm{C}$ under $12 / 12 \mathrm{~h}$ light (fluorescent)/darkness. Cultures were maintained as described by Wilson and Kaiser (32). Monoconidial isolates were paired with MAT1-1 and MAT1-2 mating-type testers (ATCC76501 and ATCC76502, respectively) (12) using the blotter paper method described by Trapero-Casas and Kaiser (30). Six to nine weeks after inoculation, the developed fruiting bodies were stained with cotton blue and examined under a light microscope at $\times 100$ and $\times 200$ to distinguish between pycnidia and pseudothecia according to characteristics described previously (30).

Effects of temperature and interrupted wetness on pseudothecium formation and maturation. The effects of temperature, wetness duration, and their interaction on pseudothecium formation and maturation were studied in a set of experiments conducted in controlled conditions. A mixture of five local MAT1-1 isolates and five local MAT1-2 isolates was used to inoculate healthy stem segments of the chickpea cv. Sfaradit. Inoculation was with the blotter paper method, and the stem segments were incubated in various conditions (as specified below) for 9 to 11 weeks. At the end of each experiment, stem segments were washed under running tap water for $2 \mathrm{~min}$ and dried on filter paper. To assess pseudothecium formation and maturation, 40 to 60 fruiting bodies (pycnidia and pseudothecia) from each of four stem segments from each treatment were dissected from the tissue, squashed in cotton blue, and examined microscopically. Each fruiting body was then categorized into one of the following groups: (i) pycnidia; (ii) immature pseudothecia (no ascospores formed and lumina filled with only pseudoparaphyses or with pseudoparaphyses and immature asci); and (iii) mature pseudothecia with asci and ascospores. The resulting data were used to determine the percentage of immature and mature pseudothecia among the total number of fruiting bodies examined (pseudothecial formation index $[P F I]$ ) and the percentage of mature pseudothecia among the total number of fruiting bodies examined (pseudothecial maturity index $[P M I])$. Each of the experiments (specified below) was repeated once.

In the first set of trials, wetness was not a limiting factor for pseudothecium formation and maturation because the stem seg- 
ments were kept wet throughout the experiments. The experiments continued for 9 weeks and were divided into three periods of 3 weeks. Chickpea stem segments inoculated with a mixture of local D. rabiei isolates of both mating types were incubated at temperatures of $5,10,15$, or $20^{\circ} \mathrm{C}$ for the first period of 3 weeks (identified hereafter as Period 1). Then, they were maintained at the same or another temperature $\left(5\right.$ to $\left.20^{\circ} \mathrm{C}\right)$ for a second period of 3 weeks (Period 2), after which they were maintained at the same or another temperature $\left(5\right.$ to $20^{\circ} \mathrm{C}$ ) for the third and final 3 -week period (Period 3). In total, there were 43 different treatments in each experiment, and treatments differed in the sequences of incubation temperatures in the three periods. For example, in one of the treatments, the stem segments were incubated at 10,5 , and $15^{\circ} \mathrm{C}$ in Periods 1,2 , and 3 , respectively. Multiple regression analysis was used to quantify the effects of the temperatures in the three incubation periods on pseudothecium formation and maturation. The dependent variables $\left(Y_{\mathrm{i}}\right)$ in the analyses were $P F I$ and $P M I$, and the independent variables were the temperatures in the different incubation periods. Linear and quadratic polynomial terms of temperatures were used in various combinations:

$$
\begin{aligned}
Y_{\mathrm{i}}= & \beta_{0}+\beta_{1} \times T_{\mathrm{P} 1}+\beta_{2} \times T_{\mathrm{P} 1}^{2}+\beta_{3} \times T_{\mathrm{P} 2}+ \\
& \beta_{4} \times T_{\mathrm{P} 2}^{2}+\beta_{5} \times T_{\mathrm{P} 3}+\beta_{6} \times T_{\mathrm{P} 3}^{2}+\varepsilon
\end{aligned}
$$

in which $\beta_{0}$ is the intercept; $\beta_{1}$ to $\beta_{6}$ are the regression coefficients; $T_{\mathrm{P} 1}, T_{\mathrm{P} 2}$, and $T_{\mathrm{P} 3}$ are the incubation temperatures in ${ }^{\circ} \mathrm{C}$ in Periods 1, 2, and 3, respectively; and $\varepsilon$ is the variability not accounted for by the model. Thirty-five regression equations were computed for each dependent variable, including various combinations of the independent variables. Equations were evaluated on the basis of the significance of the estimated parameters, the mean square error (MSE), and the coefficient of determination $\left(R^{2}\right)$.

In the second set of trials, temperature was not a limiting factor for pseudothecium formation and maturation because the stem segments were maintained at a temperature of $10^{\circ} \mathrm{C}$ (30) throughout the experiments. The experiments extended through 11 cycles of 8 days, during which chickpea stem segments that had been inoculated with a mixture of local D. rabiei isolates of both mating types were incubated in alternating wet/dry regimens. At the beginning of each cycle, the stem segments were wetted and were kept wet for a certain number of days after which they were dried, transferred to dry plates, and kept dry for the rest of that cycle. There were seven treatments that differed from each other in the number of wet days in each cycle: 0 days (stem segments remained dry throughout each cycle, i.e., throughout the whole experiment), 2, 3, 4, 5, 6, and 8 days. In the latter treatment, stem segments were maintained wet throughout each cycle, i.e., throughout the whole experiment. During the dry period of each cycle, the stem segments were placed between dry, sterile blotting papers and during the wet period they were placed between blotting papers wetted with sterile distilled water containing chloramphenicol at $250 \mathrm{ppm}$. Third-order polynomial regression was used to analyze the data. The dependent variables were PFI and PMI; the independent variables were the durations of the wet periods. The following model was used:

$$
Y_{\mathrm{i}}=\beta_{0}+\beta_{1} \times W D_{\mathrm{i}}+\beta_{2} \times W D_{\mathrm{i}}^{2}+\beta_{3} \times W D_{\mathrm{i}}^{3}+\varepsilon
$$

in which $\beta_{0}$ is the intercept; $\beta_{1}$ to $\beta_{3}$ are the regression coefficients; $W D_{\mathrm{i}}$ is the wetness duration in days; and $\varepsilon$ is the variability not accounted for by the model.

In the third set of trials, the interacting effects of temperature and wetness duration on pseudothecium formation and maturation were studied. The experiments extended over 72 days, divided into three periods of 24 days (Periods 1, 2, and 3), each of which comprised three subperiods of 8 days. The stem segments were kept wet for part of each subperiod after which they were dried and kept dry for the rest of the subperiod. In the following, these cycles are referred to as the "wet/dry cycles". The experiments comprised 12 treatments that differed in the sequences of incubation temperatures in the three periods and in the duration of wetness in each wet/dry cycle (Table 1). For example, in treatment 1, the stem segments were incubated at 15,10 , and $15^{\circ} \mathrm{C}$ in Periods 1,2 , and 3 , respectively, and were kept wet for 8 days in each wet/dry cycle, i.e., throughout the experiment. The incubation temperatures of the stem segments of treatment 3 were the same as those of treatment 1 , but they were kept wet in the first 5 days of each wet/dry cycle, dried, and kept dry for the remaining 3 days of each cycle. In some treatments, the stem segments were incubated at lower temperatures during the wet periods of each wet/dry cycle than during the dry periods to reflect the decrease of temperatures that commonly occurs on rainy days. PFI and $P M I$ were recorded for each treatment. The data were subjected to analysis of variance, and whenever the $F$-test revealed significant

Table 1. Effects of temperature (T) and wetness duration (WD) on formation and maturation of Didymella rabiei pseudothecia on chickpea stem segments ${ }^{\mathrm{x}}$

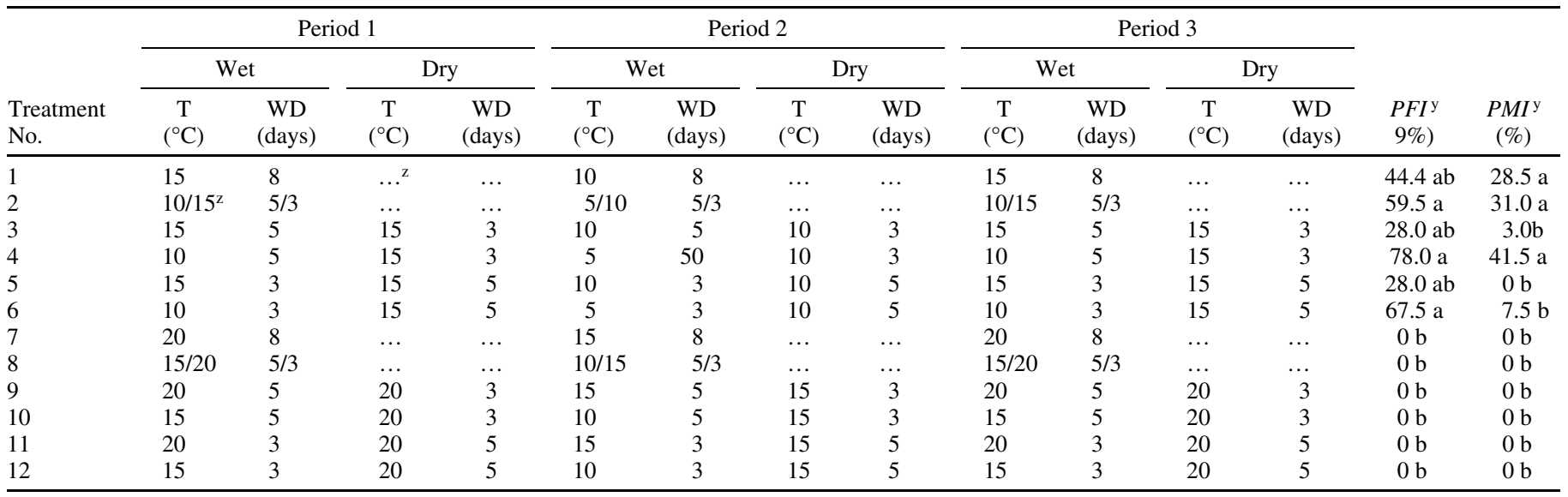

${ }^{\mathrm{x}}$ Results of two experiments. Each experiment lasted 72 days and was divided into three periods of 24 days each (Periods 1,2, and 3). Each period was subdivided into three subperiods of 8 days. Chickpea stem segments were inoculated with a mixture of Israeli $D$. rabiei isolates of both mating types, wetted, and incubated at temperature of 10,15 , or $20^{\circ} \mathrm{C}$ for 3,5 , or 8 days. Then the stem segments were dried and kept dry for the remainder of each subperiod at the same or at a different temperature. The same process was repeated in the second and third subperiods of Period 1 and in all three subperiods of Periods 2 and 3.

y $P F I=$ pseudothecium formation index. $P M I=$ pseudothecium maturity index. Within each column, numbers followed by the same letters are not significantly different according to Fisher's protected least significant difference test at $P=0.05$.

${ }^{\mathrm{z}}$ Stem segments were incubated at the first temperature for the first 5 days of each cycle and transferred to the higher temperature for the last 3 days of each cycle. ... Indicates stem segments were not dried in these treatments. 
effects, differences among treatments were determined with Fisher's protected LSD test (at $P=0.05$ ).

Dispersal of $D$. rabiei ascospores in the field. The dispersal of D. rabiei ascospores was determined indirectly in the growing seasons of 1995-1996, 1997-1998, and 1998-1999 by using chickpea plants as traps. Chickpea seed of cv. Sfaradit were sown in $10-\mathrm{cm}$-diameter pots, five seeds per pot, and maintained in a greenhouse at 20 to $25^{\circ} \mathrm{C}$ for 14 days. Then the plants were watered and taken to the Central Experimental Station of the Agricultural Research Organization at Bet Dagan where they were placed in predetermined sites adjacent to fields that were regarded as potential sources of D. rabiei ascospores. Chickpea plants had been grown in these fields in the preceding seasons (1994-1995, 1996-1997, and 1997-1998) and had been artificially inoculated with a mixture of $D$. rabiei isolates to evaluate the efficacy of various fungicides and application schedules for Ascochyta blight management. The results of those trials have been published elsewhere (27). To the best of our knowledge, there was no other source for airborne ascospores in the surrounding area since the nearest commercial chickpea fields were $>10 \mathrm{~km}$ away. In 1995 1996, trap plants were placed in eight sites, along a north-west to south-east transect at distances of 10 to $200 \mathrm{~m}$ from the source field. In 1997-1998 and 1998-1999, trap plants were placed in six sites distributed around the source field. For comparison, trap plants were also stationed each year in a site within the source field. Five pots were placed in each site, each mounted on a wooden pole at a height of $120 \mathrm{~cm}$ above ground. After being exposed to the outdoor conditions for 3 or 4 days, the trap plants
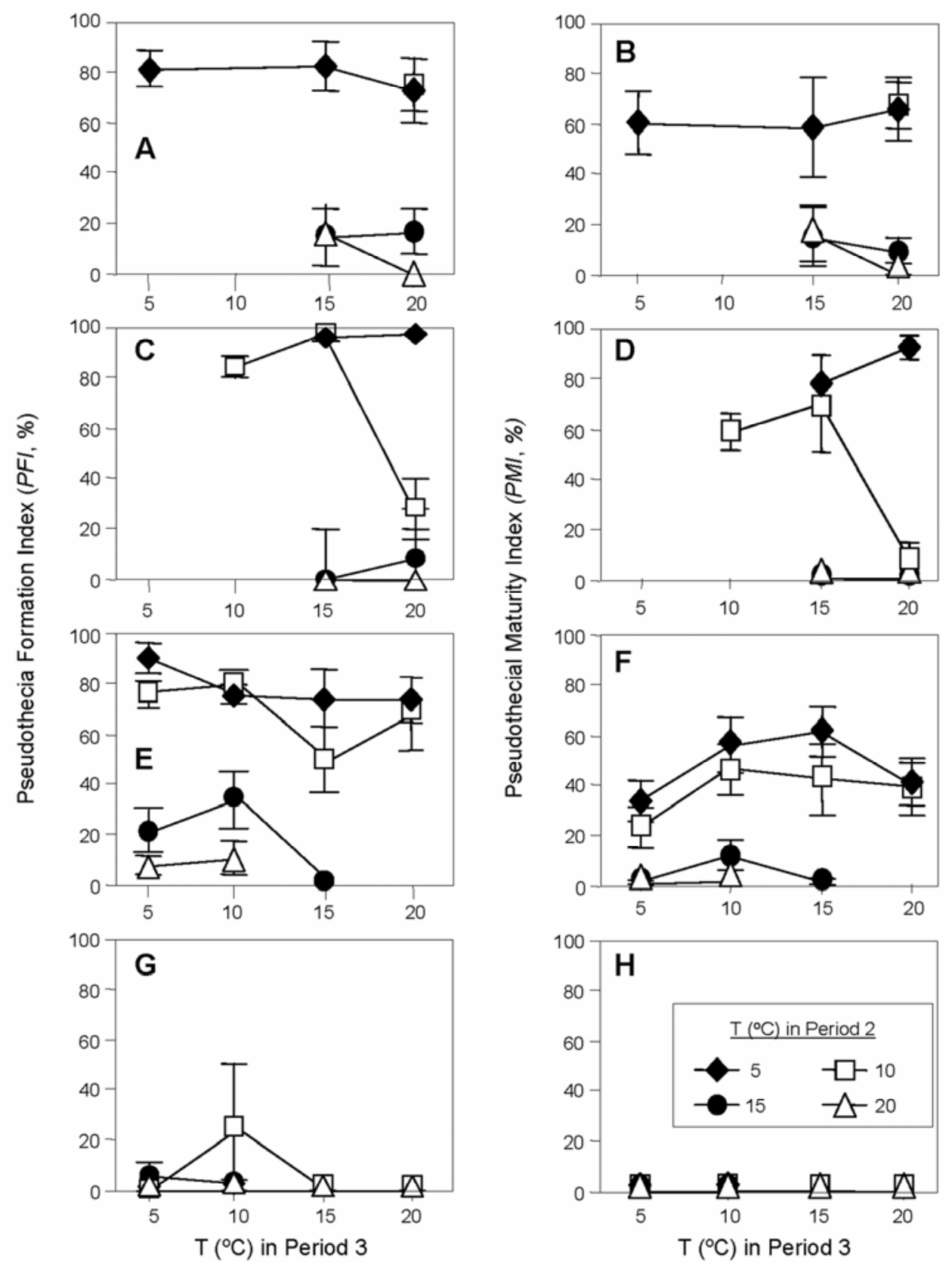

Fig. 1. Effects of temperature on the formation and maturation of Didymella rabiei pseudothecia on chickpea stem segments. The experiment continued for 9 weeks and was divided into three periods of 3 weeks each. Chickpea stem segments were inoculated with a mixture of Israeli $D$. rabiei isolates of both mating types and were incubated at $5,10,15$, or $20^{\circ} \mathrm{C}$ for the first period of 3 weeks (Period 1). Then they were maintained at the same or another temperature for a second period of 3 weeks (Period 2), after which they were maintained at the same or another temperature for a third period of 3 weeks (Period 3). The various graphs correspond to the different incubation temperatures during Period $1 . \mathbf{A}$ and $\mathbf{B}, 5^{\circ} \mathrm{C}$. $\mathbf{C}$ and $\mathbf{D}, 10^{\circ} \mathrm{C}$. $\mathbf{E}$ and $\mathbf{F}, 15^{\circ} \mathrm{C}$. $\mathbf{G}$ and $\mathbf{H}, 20^{\circ} \mathrm{C}$. Incubation temperatures in Period 2 are indicated by the different symbols within each graph, and those during Period 3 are represented along the horizontal axis of each graph. The stem segments were kept wet throughout the experiment. Vertical bars represent the SE of the mean $(n=4)$. 
were collected and a new set of trap plants was placed in each site. In 1995-1996, there were 30 sets of trap plants placed outdoors from 20 January to 31 April. In 1997-1998, there were 25 sets of trap plants in place from 22 February to 29 April, and in 1998-1999, there were 26 sets in place from 23 December to 24 March. The total numbers of trap plants were 1,200, 750, and 780 in the respective seasons.

After being exposed to outdoor conditions, the trap plants were brought back to the greenhouse. They were sprayed with water, covered with plastic bags for $24 \mathrm{~h}$, and placed in another greenhouse at $20^{\circ} \mathrm{C}$ for an additional 14 to 18 days. They were then inspected visually for Ascochyta blight symptoms. In some cases, undefined symptoms were observed. Isolation of the causal agent was performed on PDA to determine whether D. rabiei caused the lesions. Disease incidence (the percentage of trap plants exhibiting Ascochyta blight symptoms) was determined for each set of plants for each site.

\section{RESULTS}

Effects of temperature and interrupted wetness on pseudothecium formation and maturation. In the first set of trials, the sequence of temperatures at which the stem segments were incubated governed the formation and maturation of pseudothecia. Pseudothecia formed and matured on stem segments maintained at temperatures ranging from 5 to $15^{\circ} \mathrm{C}$ in Period 1 . On stem segments maintained at $20^{\circ} \mathrm{C}$, small numbers of pseudothecia were initiated but did not mature. Temperatures of $10^{\circ} \mathrm{C}$ or below in Period 2 were essential for maturation of pseudothecia. If the stem segments were incubated at 5 to $15^{\circ} \mathrm{C}$ in Period 1 and at 5 or $10^{\circ} \mathrm{C}$ in Period 2, the temperature in Period 3 had no effect on pseudothecium maturation (Fig. 1).

These findings were supported by the quantitative analyses of the data. The lowest MSE and the highest $R^{2}$ and $P$ values were observed in the equation consisting of a quadratic term for temperature in Period 1 and a linear term for temperature in Period 2. Effects of the temperature in Period 3 on PFI and PMI were not significant according to all analyses. Graphical illustration of the effects of the temperatures in Periods 1 and 2 on PFI and PMI is presented in Figure 2. Further analyses were performed for data recorded in treatments in which the temperature in Period 2 was $\leq 10^{\circ} \mathrm{C}$; the outcome of these analyses was similar, the effects of the temperature in Period 3 on PFI or PMI were not significant (data not shown).

In the second set of trials, the effects of the duration of wetness on pseudothecium formation and maturation were studied. No pseudothecia were formed on stem segments that were kept dry $(0$ wet days in each wet/dry cycle). $P F I$ increased with increasing duration of wetness in each cycle up to 3 days, remained constant up to 5 days of wetness, and decreased gradually as the number of wet days increased to eight in each wet/dry cycle (Fig. 3). The effects of the duration of wetness on $P M I$ were similar, except that $P M I$ increased gradually as the number of wet days in each cycle increased up to five and then decreased. Fewer pseudothecia were formed and matured on stem segments maintained continuously wet (i.e., 8 wet days in each wet/dry cycle) than in those exposed to an alternating 5/3 days (wet/dry) regimen (Fig. 3).

In the third set of trials, the interacting effects of temperature and wetness duration on pseudothecium formation and maturation were tested. No pseudothecia formed in treatments 7 to 12 in which the stem segments were maintained continuously or with interruptions at $20^{\circ} \mathrm{C}$ in Period 1 (Table 1). In contrast, pseudothecia were formed and matured in treatments 1 to 6 in which the stem segments were maintained at 10 or $15^{\circ} \mathrm{C}$ in Period 1: more pseudothecia were formed on stem segments that were exposed to lower temperatures during the wet periods of each wet/dry cycle than on those that were held at the same temperature (treatments 2, 4, and 6 compared with treatments 1, 3, and 5; Table 1). Furthermore, significantly more pseudothecia matured on stem segments that were wet for 5 days in each wet/dry cycle at temperatures of $10 / 15^{\circ} \mathrm{C}$ than on those that were wet for 3 days in each cycle (treatment 4 compared with treatment 6 ; Table 1), and the value of $P M I$ was not significantly different from that observed in the comparable continuously wet treatments (treatment 4 compared with treatments 1 and 2; Table 1).

Dispersal of $\boldsymbol{D}$. rabiei ascospores in the field. The dispersal of ascospores was determined by deploying chickpea traps plant over three seasons. The rainfall in 1995-1996 was close to the annual average, with $552 \mathrm{~mm}$ of rain in Bet Dagan (average annual precipitation of $550 \mathrm{~mm}$ ). Trap plants were infected by $D$. rabiei ascospores by early February; high levels of disease (i.e., disease incidence $>30 \%$ ) were observed for the first time in midFebruary, after which they persisted as long as there was rainfall. In general, rain seemed to trigger ascospore dispersal as reflected

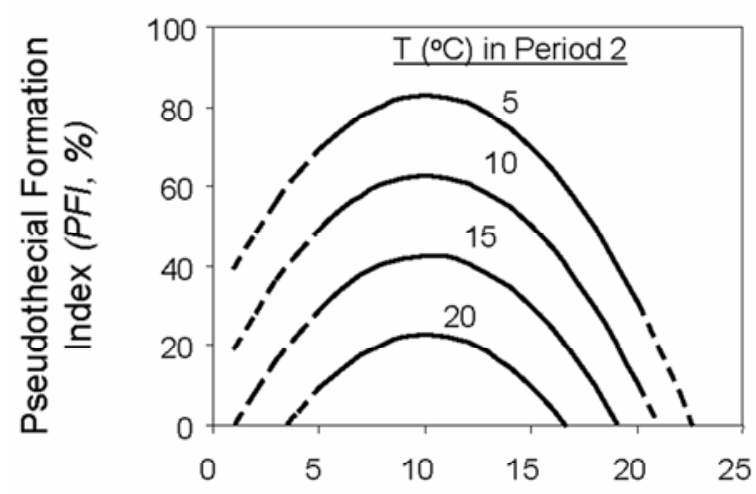

$\mathrm{T}\left({ }^{\circ} \mathrm{C}\right)$ in Period 1
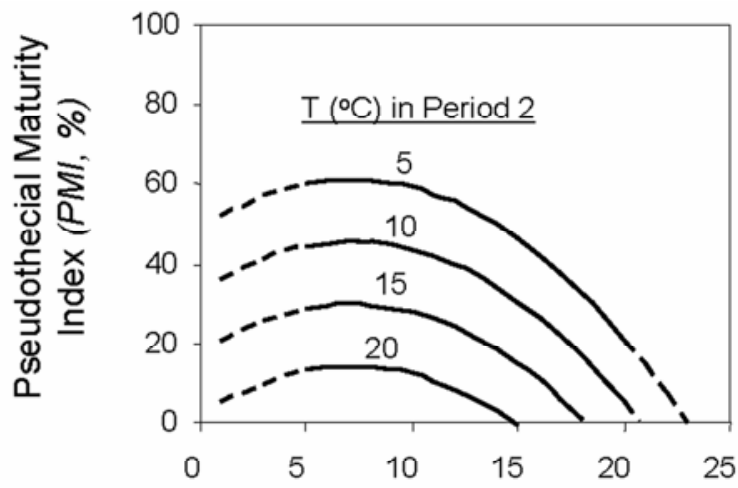

$\mathrm{T}\left({ }^{\circ} \mathrm{C}\right)$ in Period 1

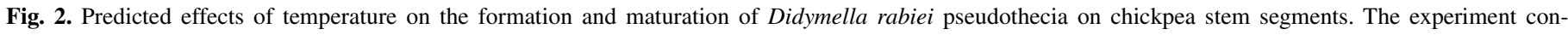

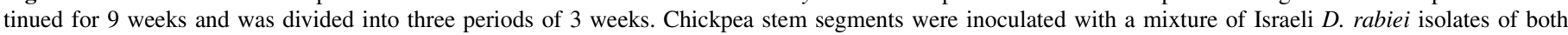

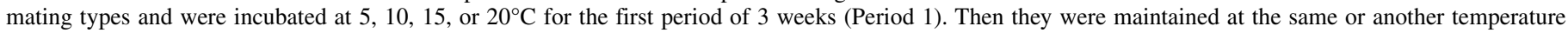

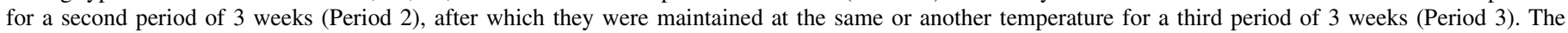

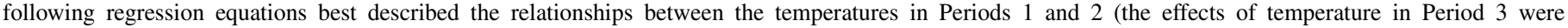

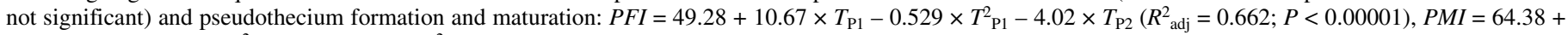

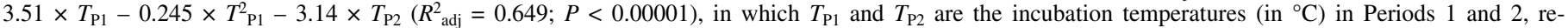

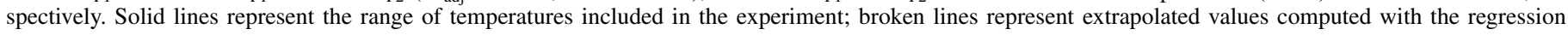
equations. 
in the infection of the trap plants, but the trap plants were also infected during rainless periods up to 1 week after rain (Fig. 4A). In 1997-1998, rainfall was slightly below the annual average $(486 \mathrm{~mm})$. Some trap plants were infected by D. rabiei ascospores as soon as they were placed outdoors, but high levels of disease were observed only in mid-March. As in 1995-1996, rain appeared to trigger the dispersal of ascospores, and in that season only a few trap plants were infected when placed outdoors in rainless periods. Trap plants continued to be infected as long as there was rainfall (Fig. 4B). The 1998-1999 season was very dry with a total of only $284 \mathrm{~mm}$ of rain. None of the trap plants among the 26 sets placed outdoors exhibited Ascochyta blight symptoms (data not shown).

\section{DISCUSSION}

Results of the current study revealed the importance of the teleomorph stage of D. rabiei in a Mediterranean climate where the rare prevalence of low temperatures and the infrequent occurrence of rain, should in theory, have precluded its development. In addition, the results provide information that may be valuable for the development of Ascochyta blight management strategies. First, it was attempted to clarify whether the temperature and wetness requirements for pseudothecium formation and maturation in D. rabiei isolates from Israel differ from those reported for isolates from the Pacific Northwest United States or Spain. For the Israeli isolates, when moisture was not a limiting factor, the initial stages of pseudothecium formation occurred at temperatures ranging from 5 to $15^{\circ} \mathrm{C}$, but temperatures of $\leq 10^{\circ} \mathrm{C}$ were essential for pseudothecium maturation; if these temperature requirements were satisfied, subsequent pseudothecium development was independent of temperature within the tested range. When temperature was not a limiting factor, wetness was essential for pseudothecium formation and maturation. No pseudothecia were formed on stem segments that were kept dry. On the whole, these requirements are similar to those published by Trapero-Casas and Kaiser (30) for Pacific Northwest isolates and by Navas-Cortés et al. (21) for Spanish isolates. This suggests that D. rabiei isolates from Israel were not necessarily adapted to the local Mediterranean climate. Alternatively, it may imply that the teleomorph stage is produced in marginal temperature and wetness conditions not included in the previous studies.

The first requirement that was presumed not to be satisfied under the Mediterranean climate of Israel was the prevalence of long periods with low temperatures during pseudothecium development. Nevertheless, the results of the current study suggest that pseudothecia may form and mature on stem segments that are incubated at low temperatures for only three successive weeks as well as on those incubated at low temperatures during periods of as little as 3 days separated by periods with higher temperatures. The other requirement that was assumed not to be satisfied in the Mediterranean climate of Israel was the occurrence of prolonged periods of wetness. However, the results of this study suggest that pseudothecia may form and mature on stem segments maintained wet during periods of only 3 days separated by dry periods. These data imply that the short, interrupted periods of low temperature

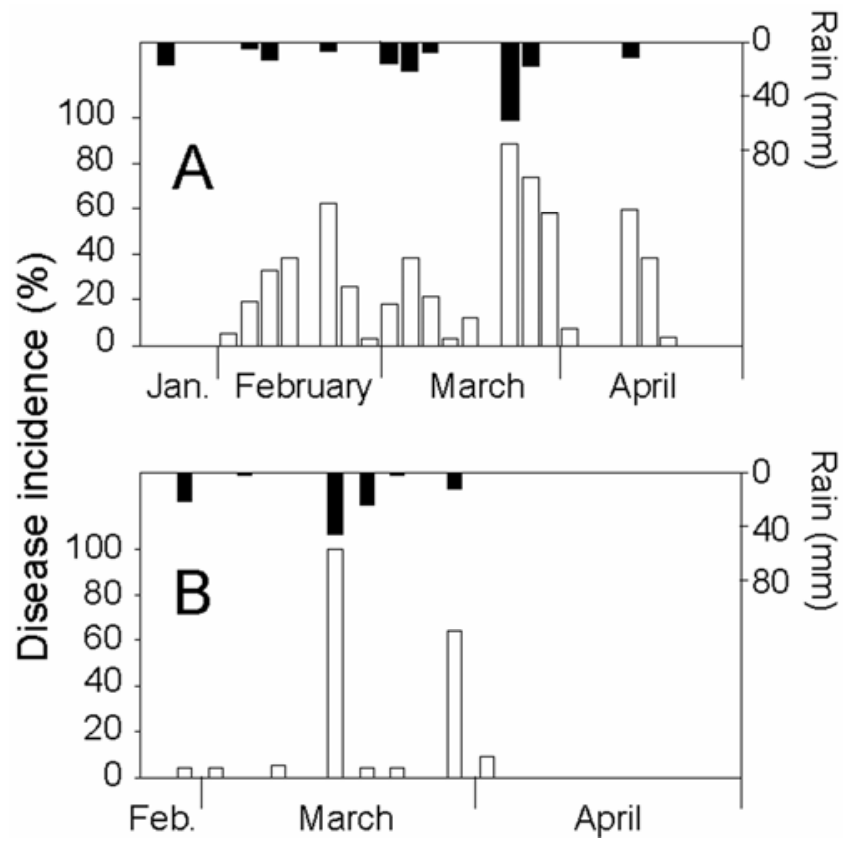

Fig. 4. Incidence of Ascochyta blight on chickpea trap plants exposed to airborne ascospores of Didymella rabiei for 3 or 4 days during the A, 1995-1996 and B, 1997-1998 field seasons (white bars) and the quantity of rain during the same periods (black bars). Trap plants were placed near fields with $D$. rabieiinfested chickpea debris from the preceding seasons. Source fields were located in the Central Experimental Station of the Agricultural Research Organization at Bet Dagan, Israel. Each bar in the histogram represents the mean incidence of five pots (five plants per pot).
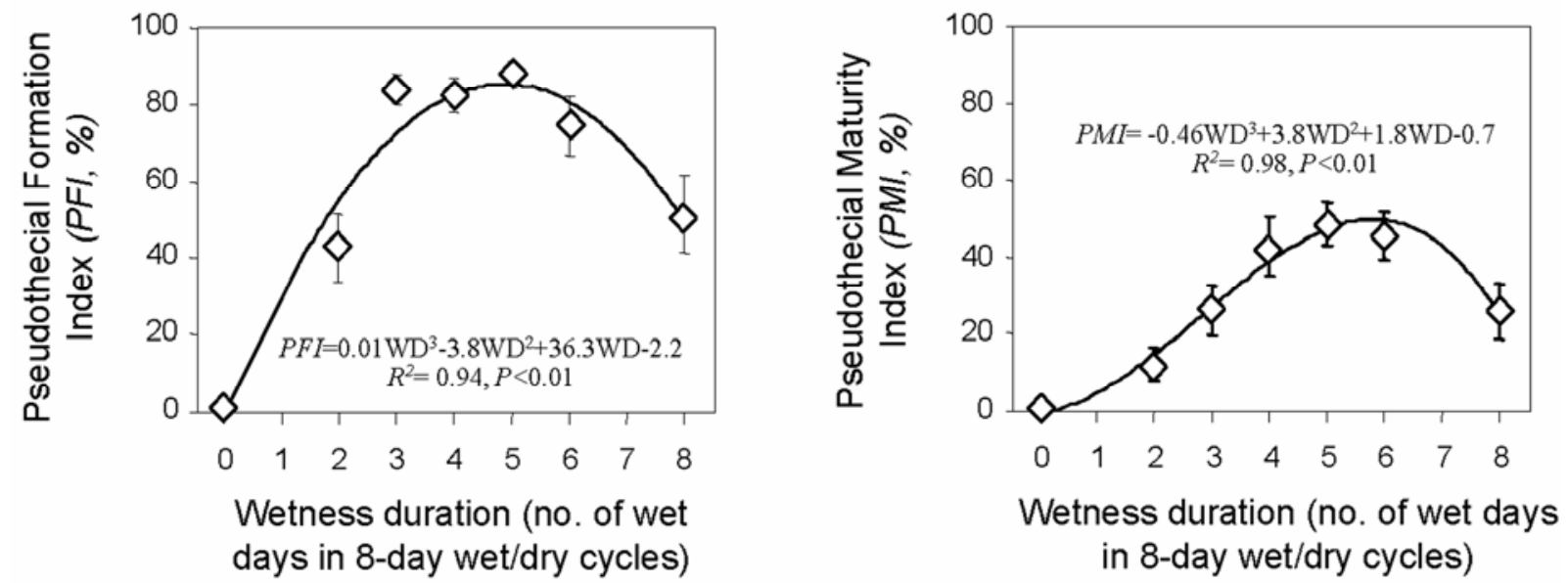

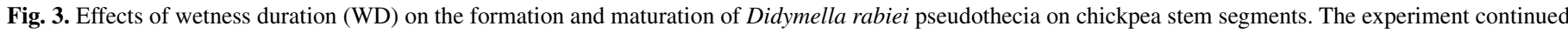

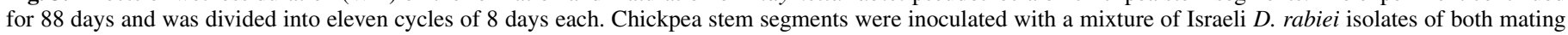

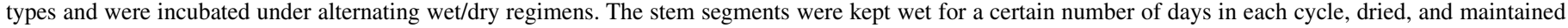

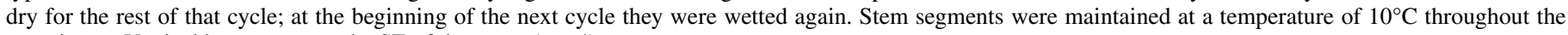
experiment. Vertical bars represent the SE of the mean $(n=4)$. 
and wetness satisfy the requirements for formation and maturation of $D$. rabiei pseudothecia. Presumably, these conditions prevail in the Mediterranean climate of Israel and are sufficient for production and maturation of $D$. rabiei pseudothecia. Maturation of pseudothecia in wet/dry cycles has been reported for $M$. citri (19) and V. inaequalis (23).

A combination of splashing rain with strong winds may spread D. rabiei pycnidiospores or infected plant debris over considerable distances (10). Despite that, it was assumed that the Ascochyta blight symptoms developed on trap plants in the current study were caused by the teleomorph rather than by the anamorph stage of the pathogen. Several considerations led us to this conclusion. First, if pycnidiospores were the infecting propagules on the trap plants, the plants should have been infested during the rains of late January 1996 and late February 1998 since pycnidia were present on the infested plant debris in the source fields. Moreover, at least some of the 26 sets of trap plants placed outdoors in 1998-1999 should have been infected. In 1998-1999, the trap plants were exposed to 21 rainy days ( $\geq 1 \mathrm{~mm}$ of rain) with $256 \mathrm{~mm}$ of rain in total. Second, if the anamorph was the source of initial infections, then trap plants placed within the source fields should have been infected more severely than those placed outside since pycnidiospores are dispersed mostly over short distances (10). In fact, the trap plants placed within the source fields were infected with comparable severity to those placed outside, which implies that the initial inoculum was airborne.

Analysis of the trap plants data provided insight into the dispersal of ascospores in time and space. Discharge of ascospores was apparently triggered by rain, which was expected given previous observations for $D$. rabiei $(10,21,30)$ and other pseudotheciumproducing fungi $(16,19,24,25,29)$. Our current results also agree with those of Trapero-Casas et al. (31) who found that ascospore dissemination depended more on the occurrence of rain than on its amount. On the other hand, trap plants were occasionally infected during rainless exposure periods in 1995-1995; these occurred mainly after rain events prior to the exposure period. Similar phenomena were reported by others $(18,31)$.

Results of the current and previous studies $(10,22,30,31)$ have facilitated modeling of the events leading to the production of the teleomorph stage of $D$. rabiei in the Mediterranean climate of Israel. There are several underlying assumptions: (i) pseudothecia may develop and mature in a discontinuous process; (ii) the process proceeds only when the infested plant debris is wet; (iii) rain is the main source of wetness; (iv) pseudothecium development consists of three consecutive phases, pseudothecium formation, initiation of asci and ascospores, and maturation of asci and ascospores and each having distinct temperature requirements; and (v) in rainless periods or when temperatures are unfavorable, pseudothecium development ceases but it resumes when favorable conditions return. The scenario is as follows: the formation of pseudothecia is initiated during the rains of late autumn to early winter (between October and through December, depending on the year) when temperatures drop below $15^{\circ} \mathrm{C}$. Further pseudothecium development and initial stages of maturation occur when low temperatures $\left(\leq 10^{\circ} \mathrm{C}\right)$ prevail for short periods during rainy days in mid-winter (December to February). When the low temperature requirement is satisfied, pseudothecia complete their development during the rains of late winter to early spring (January to March), independently of the temperatures. Ascospores are discharged from mature pseudothecia during the rains of spring to early summer (February to April), and are dispersed by the prevailing winds.

Wetness and temperature data and their interactions have been used to develop criteria for predicting pseudothecium maturation of other fungi $(9,22,25)$. Data of this and a previous study (5) enabled us to develop similar criteria for D. rabiei (26). Commercial chickpea growers in Israel apply these criteria in scheduling fungicidal sprays aimed at preventing infections inflicted by the teleomorph stage of the pathogen.

\section{ACKNOWLEDGMENTS}

This research was supported in part by funds from the Chief Scientist of the Israeli Ministry of Agriculture and Rural Development. Contribution number 520/04 from the Agricultural Research Organization, the Volcani Center, Bet Dagan 50250, Israel.

\section{LITERATURE CITED}

1. Armstrong, C. L., Chongo, G., Gossen, B. D., and Duczek, L. J. 2001. Mating type distribution and incidence of the teleomorph of Ascochyta rabiei, Didymella rabiei in Canada. Can. J. Plant Pathol. 23:110-113.

2. Barve, M. P., Arie, T., Salimath, S. S., Muehlbauer, F. J., and Peever, T. L. 2003. Cloning and characterization of the mating type (MAT) locus from Ascochyta rabiei (teleomorph: Didymella rabiei) and a MAT phylogeny of legume-associated Ascochyta spp. Fungal Genet. Biol. 39:151167.

3. Gadoury, D. M., Stensvand, A., and Seem, R. C. 1998. Influence of light, relative humidity, and maturity of populations on discharge of ascospores of Venturia inaequalis. Phytopathology 88:902-909.

4. Galloway, J., and MacLeod, W. J. 2003. Didymella rabiei, the teleomorph of Ascochyta rabiei, found on chickpea stubble in Western Australia. Aust. Plant Pathol. 32:127-128.

5. Gamliel, E. 2000. Integrated management of Didymella rabiei, the teleomorph stage of Ascochyta rabiei, in Israel. (In Hebrew, with English abstract) M.S. thesis. Hebrew University of Jerusalem.

6. Gamliel, E., Shtienberg, D., Vintal, H., and Dinoor, A. 2000. Development and maturation of pseudothecia of Didymella rabiei on chickpea straw. Phytoparasitica (Abstr.) 28:284.

7. Gorlenko, M. V., and Bushkova, L. N. 1958. Perfect state of the causal agent of ascochytosis of chickpea. Rev. Appl. Mycol. 37:695.

8. Haware, M. P. 1987 Occurrence of the perfect state of Ascochyta rabiei in Syria. Int. Chickpea Newsl. 17:29-30.

9. James, J. R., and Sutton, T. B. 1982. Environmental factors influencing pseudothecial development and ascospore maturation of Venturia inaequalis. Phytopathology 72:1073-1080.

10. Kaiser, W. J. 1992. Epidemiology of Ascochyta rabiei. Pages 117-134 in: Disease Resistance Breeding in Chickpea. Proc. Consul. Meeting on Breeding for Disease Resistance in Kabuli Chickpea. K. B. Singh and M. C. Saxena, eds. ICARDA, Aleppo, Syria.

11. Kaiser, W. J., and Hannan, R. M. 1987. First report of Mycosphaerella rabiei on chickpeas in the Western hemisphere. Plant Dis. 71:192.

12. Kaiser, W. J., and Küsmenoglu, I. 1997. Distribution of mating types and the teleomorph of Ascochyta rabiei on chickpea in Turkey. Plant Dis. 81:1284-1287.

13. Kaiser, W. J., and Okhovat, M. 1996. Distribution of Didymella rabiei, the teleomorph of Ascochyta rabiei, in Iran. Iran. J. Plant Pathol. 158-162.

14. Kovachevski, I. C. 1936. The blight of chickpea (Cicer arietinum), Mycosphaerella rabiei f. sp. Report Number 15:700. Ministry of Agriculture and National Domains, Plant Protection Institute, Sofia, Bulgaria. (In Russian with English summary).

15. Kövics, G., Holly, L., and Simay, E. I. 1986. An ascochytosis of the chickpea (Cicer arietinum L.) caused by Didymella rabiei (Kov.) v. Arx: Imperfect Ascochyta rabiei (Pass.) Lab. in Hungary. Acta Phytopathol. Entomol. Hung. 21:147-150.

16. Luley, C. J., and McNabb, H. S., Jr. 1989. Ascospore production, release, germination and infection of Populus by Mycosphaerella populorum. Phytopathology 79:1013-1018.

17. Milgroom, M. G., and Peever, T. L. 2003. Population biology of plant pathogens: The synthesis of plant disease epidemiology and population genetics. Plant Dis. 87:608-617.

18. Mondal, S. N., Gottwald, T. R., and Timmer, L. W. 2003. Environmental factors affecting the release and dispersal of ascospores of Mycosphaerella citri. Phytopathology 93:1031-1036.

19. Mondal, S. N., Howd, D. S., Brlansky, R. H., and Timmer, L. W. 2004. Mating and pseudothecial development in Mycosphaerella citri, the cause of citrus greasy spot. Phytopathology 94:978-982.

20. Navas-Cortés, J. A., Trapero-Casas, A., and Jimémez-Díaz, R. M. 1995. Survival of Didymella rabiei in chickpea straw in Spain. Plant Pathol. 44:332-339.

21. Navas-Cortés, J. A., Trapero-Casas, A., and Jimémez-Díaz, R. M. 1998. Influence of relative humidity and temperature on development of Didymella rabiei in chickpea debris. Plant Pathol. 47:57-66.

22. Navas-Cortés, J. A., Trapero-Casas, A., and Jimémez-Díaz, R. M. 1998. Phenology of Didymella rabiei development on chickpea debris under field conditions in Spain. Phytopathology 88:983-991.

23. O'Leary, A. L., and Sutton, T. B. 1986. The influence of temperature and moisture on the quantitative production of pseudothecia of Venturia inaequalis. Phytopathology 76:199-204. 
24. Pinkerton, J. N., Johnson, K. B., Stone, J. K., and Ivors, K. L. 1998. Factors affecting release of ascospores of Anisogramma anomala. Phytopathology 88:122-128.

25. Prados-Ligero, A. M., Gonzalez-Andujar, J. L., Melero-Vara, J. M., and Basallote-Ureba, M. J. 1998. Development of Pleospora allii on garlic debris infected by Stemphylium vesicarium. Eur. J. Plant Pathol. 104:861-870.

26. Shtienberg, D., Gamliel-Atinsky, E., Retig, B., Brener, S., and Dinoor, A. 2005. Significance of preventing primary infections by Didymella rabiei and development of a model to estimate the maturity of pseudothecia. Plant Dis. 89:1027-1034.

27. Shtienberg, D., Vintal, H., Brener, S., and Retig, B. 2000. Rational management of Didymella rabiei in chickpea by integration of genotype resistance and post infection application of fungicides. Phytopathology 90:834-842.

28. Shtienberg, D., Vintal, H., Nitzani, Y., Brener, S., and Retig, B. 1998. The perfect stage of Ascochyta blight (Didymella rabiei): A new threat to chickpea production in Israel? Phytoparasitica (Abstr.) 26:157.

29. Sutton, T. B. 1981. Production and dispersal of ascospores and conidia by Physalospora obtusa and Botryosphaeria dothidea in apple orchards. Phytopathology 71:584-589.

30. Trapero-Casa, A., and Kaiser, W. J. 1992. Development of Didymella rabiei, the teleomorph of Ascochyta rabiei, on chickpea straw. Phytopathology 82:1261-1266.

31. Trapero-Casas, A., Navas-Cortés, J. A., and Jiménez-Díaz, R. M. 1996. Airborne ascospores of Didymella rabiei as a major primary inoculum for Ascochyta blight epidemics in chickpea crops in southern Spain. Eur. J. Plant Pathol. 102:237-245.

32. Wilson, A. D., and Kaiser, W. J. 1995. Cytology and genetics of sexual incompatibility in Didymella rabiei. Mycologia 87:795-804.

33. Zachos, D. G., Panagopoulos, C. G., and Makris, S. A. 1963. Recherches sur la biologie, l'epidemiologie et la lutte contre l'anthracnose du poischiche. Ann. Inst. Phytopathol. Benaki 5:167-192. 